\title{
Regarding "Measured Head CT/CTA Skin Dose and Intensive Care Unit Patient Cumulative Exposure"
}

W e thank Nawfel and Young ${ }^{1}$ for their thoughtful article, "Measured Head CT/CTA Skin Dose and Intensive Care Unit Patient Cumulative Exposure." Nawfel and Young ${ }^{1}$ have published a timely study in the midst of recent positive neurointerventional stroke trials and the resultant increased volume of CT angiographic imaging. Radiation exposure from medical imaging is always part of the risk-benefit analysis for critically ill patients. Accurate radiation dosimetry has been a topic of much debate in recent years, both from a scientific standpoint and from patient concerns sparked by the lay press. We would like to discuss the conclusions from Nawfel and Young ${ }^{1}$ regarding radiation exposure from head CT/CTA in the context of the current medical literature and the potential future directions for research.

The authors did not find a statistically significant correlation between patient head size and peak skin dose. The peak skin dose was found to be consistently lower than the volumetric CT dose index $\left(\mathrm{CTDI}_{\mathrm{vol}}\right)$, citing the use of a "correction factor" with no additional variable. However, McCollough et $\mathrm{al}^{2}$ summarized an exponential relationship between patient size (sum of anteroposterior $[\mathrm{AP}]$ and lateral diameters) and patient dose at other sites such as the abdomen. Perhaps the patient sample size was not sufficient to include enough variability to make an exponential relationship apparent. In addition, adult head size does not vary as widely as abdominal girth. The homogeneity of adult head size in the available cohort of patients may not sufficiently power for accurate statistical analysis. Perhaps either a much larger cohort or the inclusion of a pediatric patient population would have introduced the size heterogeneity necessary to make clear whether the exponential relationship between patient size and dose applies to head imaging as it does for the abdomen.

Whereas the authors used the geometric mean to represent head size, other surrogates for size have been cited in the literature, such as weight, body mass index, single AP or single lateral diameter from either the localizer image or an axial cross-

http://dx.doi.org/10.3174/ajnr.A5234 sectional image, summative AP and lateral diameters, and effective diameters. ${ }^{3}$ Work by the American Association of Physicists in Medicine $\mathrm{e}^{3}$ has also identified water-equivalent diameter $\left(\mathrm{D}_{\mathrm{W}}\right)$ as a surrogate for patient size in thoracic and abdominal imaging. In addition to measuring patient size, the application of $\mathrm{D}_{\mathrm{W}}$ in the head would also take into account the variable attenuation properties ranging from air within paranasal sinuses to sclerotic calvaria. In fact, recent work by Anam et $\mathrm{al}^{4}$ has demonstrated an exponential relationship between a normalized size-specific dose estimate and $\mathrm{D}_{\mathrm{W}}$ for head CT, including automation of the $\mathrm{D}_{\mathrm{W}}$ calculation as others have previously described. Perhaps $\mathrm{D}_{\mathrm{W}}$ or one of the other surrogates of patient size might have been useful in the study by Nawfel and Young ${ }^{1}$ to elucidate the exponential relationship with size-specific dose estimate.

Disclosures: Michele Johnson—UNRELATED: Board Membership: Continuum Health, Comments: nonprofit board with no compensation.

\section{REFERENCES}

1. Nawfel RD, Young GS. Measured head CT/CTA skin dose and intensive care unit patient cumulative exposure. AJNR Am J Neuroradiol 2017;38:455-61 CrossRef Medline

2. McCollough $\mathrm{CH}$, Leng $\mathrm{S}$, Yu L, et al. CT dose index and patient dose: they are not the same thing. Radiology 2011;259:311-16 CrossRef Medline

3. American Association of Physicists in Medicine. Use of Water Equivalent Diameter for Calculating Patient Size and Size-Specific Dose Estimates (SSDE) in CT. The Report of AAPM Task Group 220. College Park, Maryland: American Association of Physicists in Medicine; 2014. AAPM report no. 220

4. Anam C, Haryanto F, Widita R, et al. Automated calculation of waterequivalent diameter (DW) based on AAPM Task Group 220. J Appl Clin Med Phys 2016;17:320-33 CrossRef Medline

(D) Ikuta

(1) A. Mustafa

(D) M.H. Johnson

Department of Radiology \& Biomedical Imaging Yale University School of Medicine New Haven, Connecticut 